\title{
BMJ Open Characterising variation in composition and activation criteria of rapid response and cardiac arrest teams: a survey of Medicare participating hospitals in five American states
}

To cite: Mitchell 0JL, Motschwiller CW, Horowitz JM, et al. Characterising variation in composition and activation criteria of rapid response and cardiac arrest teams: a survey of Medicare participating hospitals in five American states. BMJ Open 2019;9:e024548. doi:10.1136/ bmjopen-2018-024548

- Prepublication history and additional material for this paper are available online. To view these files, please visit the journal online (http://dx. doi org/10.1136/bmjopen-2018024548).

Received 1 June 2018 Revised 11 January 2019 Accepted 5 February 2019

Check for updates

(C) Author(s) (or their employer(s)) 2019. Re-use permitted under CC BY-NC. No commercial re-use. See rights and permissions. Published by BMJ.

${ }^{1}$ Department of Internal Medicine, New York University School of Medicine, New York City, New York, USA

${ }^{2}$ Division of Cardiology, New York University School of Medicine, New York City, New York, USA ${ }^{3}$ Division of Pulmonary, Critical Care and Sleep Medicine,

New York University School of Medicine, New York City, New York, USA

Correspondence to

Dr Oscar J L Mitchell; oscarmitchell@mac.com

\section{ABSTRACT}

Objectives To characterise the variation in composition, leadership, and activation criteria of rapid response and cardiac arrest teams in five north-eastern states of the USA.

Design Cross-sectional study consisting of a voluntary 46-question survey of acute care hospitals in northeastern USA.

Setting Acute care hospitals in New York, New Jersey, Rhode Island, Vermont, and Pennsylvania.

Participants Surveys were completed by any member of the rapid response team (RRT) with a working knowledge of team composition and function. Participants were all Medicare-participating acute care hospitals, including teaching and community hospitals as well as hospitals from rural, urban and suburban areas.

Results Out of 378 hospitals, contacts were identified for 303 , and 107 surveys were completed. All but two hospitals had an RRT, 70\% of which changed members daily. The most common activation criteria were clinical concern (95\%), single vital sign abnormalities (77\%) and early warning score (59\%). Eighty one per cent of hospitals had a dedicated cardiac arrest team. RRT composition varied widely, with respiratory therapists, critical care nurses, physicians and nurse managers being the most likely to attend (89\%, 78\%, 64\% and 51\%, respectively). Consistent presence of critical care physicians was uncommon and both cardiac arrest teams and teams were frequently led by trainee physicians, often without senior supervision.

Conclusions As the largest study to date in the USA, we have demonstrated wide heterogeneity, rapid team turnover and a lack of senior supervision of RRT and cardiac arrest teams. These factors likely contribute to the mixed results seen in studies of RRTs.

\section{INTRODUCTION}

The use of rapid response teams (RRTs) is now well established throughout the USA, Europe, Australia and Canada, in part due to their inclusion in the Institute for Healthcare Improvement (IHI) 5 Million Lives

\section{Strengths and limitations of the study}

- Survey based design of the study and $35 \%$ response rate limits the generalisability of our findings.

- Design of survey allowed for detailed description of cardiac arrest team (CAT) and rapid response team (RRT) composition and function in participating hospitals.

- Only represents Medicare participating hospitals in five states.

Campaign. ${ }^{1}$ Although no criteria have been formally defined, the IHI defines an RRT as 'a team of clinicians who bring critical care expertise to the bedside'. In practice the composition of each RRT likely varies by hospital, based on local resources and requirements. Once activated, the goal of the RRT is to rescue sick or deteriorating patients to prevent further decompensation and to facilitate appropriate and timely treatment, as well as rapid and appropriate escalation of care. Each RRT may be a multidisciplinary team with representatives from internal medicine, critical care and nursing, as well as other allied healthcare professionals. ${ }^{2-4}$

Evidence behind RRTs is far from robust, with some studies showing reductions in rates of unexpected hospital deaths and out of intensive care unit (ICU) cardiac arrest after the establishment of an RRT $^{5-11}$ and others failing to demonstrate significant improvement. $^{21213}$ The effectiveness of an RRT might be intrinsically linked to its composition, as provider expertise possibly influences the ability to promptly stabilise, resuscitate and triage a deteriorating patient. Most of the published literature, however, is focused on the impact on patient outcomes after implementation of an RRT in a single hospital or 
healthcare system, with little attention to RRT and cardiac arrest team composition. To our knowledge, there have been only two such studies in the USA, one which described substantial heterogeneity between 33 hospitals in a south-eastern state, and another that showed variation in cardiac arrest team (CAT) composition. ${ }^{414}$

We hypothesised that there would be wide variation in the leadership, activation criteria, and the composition of RRT and cardiac arrest teams. We sought to survey acute care hospitals in five north-eastern states: New York; Pennsylvania; Rhode Island; Vermont and New Jersey in order to establish the current practice with regards to RRT and cardiac arrest team members, availability and activation criteria.

\section{METHODS}

\section{Survey design}

A 46-question survey was created by the investigators (online supplementary appendix 1 ). The survey collected baseline hospital characteristics, which were limited to hospital size, ICU beds and the presence of an Accreditation Council for Graduate Medical Education (ACGME) training programme to avoid loss of anonymity. Characteristics of the RRT included methods of RRT activation, including the use of early warning scores (EWS), single vital sign abnormalities and clinical concern. Additionally, information on RRT and cardiac arrest team leadership and individual team composition was collected, with the RRT leader being defined as the member of the team who usually leads the RRT.

\section{Survey distribution}

The study was conducted over a 3-month period from January to March 2018. Acute care hospitals in New York, Pennsylvania, Rhode Island, Vermont and New Jersey were identified from the publicly available Medicare database (data.medicare.gov). If contact details were not already known to team members or available online, hospitals were contacted by telephone by study team members in order to identify a contact person involved in RRTs and cardiac arrests. Study team members contacted hospital personnel in a systematic fashion: initially contacting the nursing administration department; then the hospitalist or medicine division; then chief residents of the internal medicine programme (if available); and finally the Chief Nursing Officer of the hospital. Once an appropriate contact was identified, an anonymous survey email was sent via the Health Insurance Portability and Accountability Act of 1996 compliant REDCap web application. After 2 weeks, a reminder email was sent if the survey had not been completed.

To minimise the risk of duplicate surveys being completed, each survey contained a unique link, and only one valid link was sent to each hospital at a time. All survey questions had to be completed in order to submit the survey.
Table 1 Characteristics of participating hospitals

Characteristics of participating hospitals

\begin{tabular}{|c|c|c|}
\hline & $\mathbf{n}$ & Percentage \\
\hline \multicolumn{3}{|l|}{ University affiliation } \\
\hline Yes & 59 & 55 \\
\hline No & 48 & 45 \\
\hline \multicolumn{3}{|l|}{ Financial structure } \\
\hline Private & 54 & 50 \\
\hline Public & 53 & 50 \\
\hline \multicolumn{3}{|l|}{ Inpatient beds } \\
\hline $0-500$ & 72 & 67 \\
\hline$>500$ & 35 & 33 \\
\hline \multicolumn{3}{|l|}{ ICU beds } \\
\hline 0 & 2 & 2 \\
\hline $1-20$ & 50 & 47 \\
\hline $21-50$ & 31 & 29 \\
\hline$>50$ & 24 & 22 \\
\hline \multicolumn{3}{|c|}{ ACGME training programme present } \\
\hline $\begin{array}{l}\text { Internal medicine } \\
\text { residency }\end{array}$ & 69 & 64 \\
\hline Anaesthesia residency & 39 & 36 \\
\hline Critical care fellowship & 51 & 48 \\
\hline
\end{tabular}

ACGME, Accreditation Council for Graduate Medical

Education; ICU, intensive care unit.

Statistical comparisons of categorical variables were performed using the $\chi^{2}$ test. Data analysis was completed using the Statistical Package for the Social Sciences (SPSS) V.25.

\section{Patient involvement}

Neither patients, nor the general public were involved in this research project.

\section{RESULTS}

\section{Characteristics of the study hospitals}

Three hundred and seventy-eight acute care hospitals were identified from the Medicare database and RRT contacts were identified for 303 of these $(80 \%)$ using the methods above. One hundred and seven surveys were completed, the majority from New York and Pennsylvania, a response rate of $35 \%$. As all questions were mandatory, there were no missing data.

Out of the hospitals that responded, 59 (55\%) reported a university affiliation. All but two hospitals had an ICU (table 1). Seventy-two hospitals $(67 \%)$ had a training programme approved by the ACGME in Internal Medicine, Anaesthesia, or Critical Care.

\section{RRT activation criteria and availability}

Of the 107 hospitals, 105 had an RRT. One of the two hospitals without an ICU also did not have an RRT. One 
Table 2 RRT characteristics, including availability of RRT, activation criteria, mechanism of dispatch, and variation in individual team members

\begin{tabular}{|c|c|c|}
\hline \multicolumn{3}{|c|}{ RRT characteristics } \\
\hline & $\mathbf{n}$ & Percentage \\
\hline 24 hours RRT & 104 & 99 \\
\hline \multicolumn{3}{|l|}{ RRT calling criteria } \\
\hline Clinical concern & 100 & 95 \\
\hline Vital sign & 81 & 77 \\
\hline EWS & 62 & 59 \\
\hline \multicolumn{3}{|l|}{ RRT called over } \\
\hline Overhead & 75 & 71 \\
\hline Pager & 71 & 68 \\
\hline Phone & 24 & 23 \\
\hline $\begin{array}{l}\text { Pager and } \\
\text { overhead }\end{array}$ & 49 & 47 \\
\hline \multicolumn{3}{|c|}{ RRT team members change } \\
\hline Daily & 73 & 70 \\
\hline Weekly & 15 & 14 \\
\hline Monthly & 4 & 4 \\
\hline Rarely & 13 & 12 \\
\hline
\end{tabular}

EWS, early warning scores; RRT, rapid response team.

hundred and four of the 105 RRTs were available 24 hours a day. RRTs were dispatched by overhead call in 75 hospitals $(71 \%)$, pager in 71 hospitals $(68 \%)$ and by phone in
24 hospitals (23\%). Over half of the RRTs were called out with more than one modality, the most common of which was a combination of pager and overhead call in 49 hospitals $(47 \%)$.

\section{Membership turnover}

Turnover of the RRT was high, with team members changing daily in $70 \%$. The majority of hospitals had multiple activation criteria for RRTs, the most common of which were clinical concern $(95 \%)$, vital sign abnormalities $(77 \%)$, and EWS (59\%) (table 2). Less common activation criteria included family member concern (2\%), alcohol withdrawal scores (1\%) falls (1\%), and lack of intravenous access (1\%). Neither the size of the hospital nor the size of the ICU was significantly associated with the use of EWS as activation criteria $(p=0.48$ and $\mathrm{p}=0.33$, respectively).

\section{RRT composition}

RRT composition varied widely with most hospitals having representatives from multiple disciplines including physicians, nursing management, respiratory therapy and pharmacy. Respiratory therapists, critical care nurses, physicians and nurse managers were the most common healthcare professionals to always attend RRTs $(89 \%$, $78 \%, 64 \%$ and $51 \%$, respectively) (figure 1). Sixty-seven hospitals $(64 \%)$ always had a physician present in the RRT. Attending physicians were always part of the RRT in 40 hospitals (38\%), occasionally present in 56 (53\%) and never present in $9(9 \%)$. Critical care physicians, whether attending or fellow, always attended RRT activations in

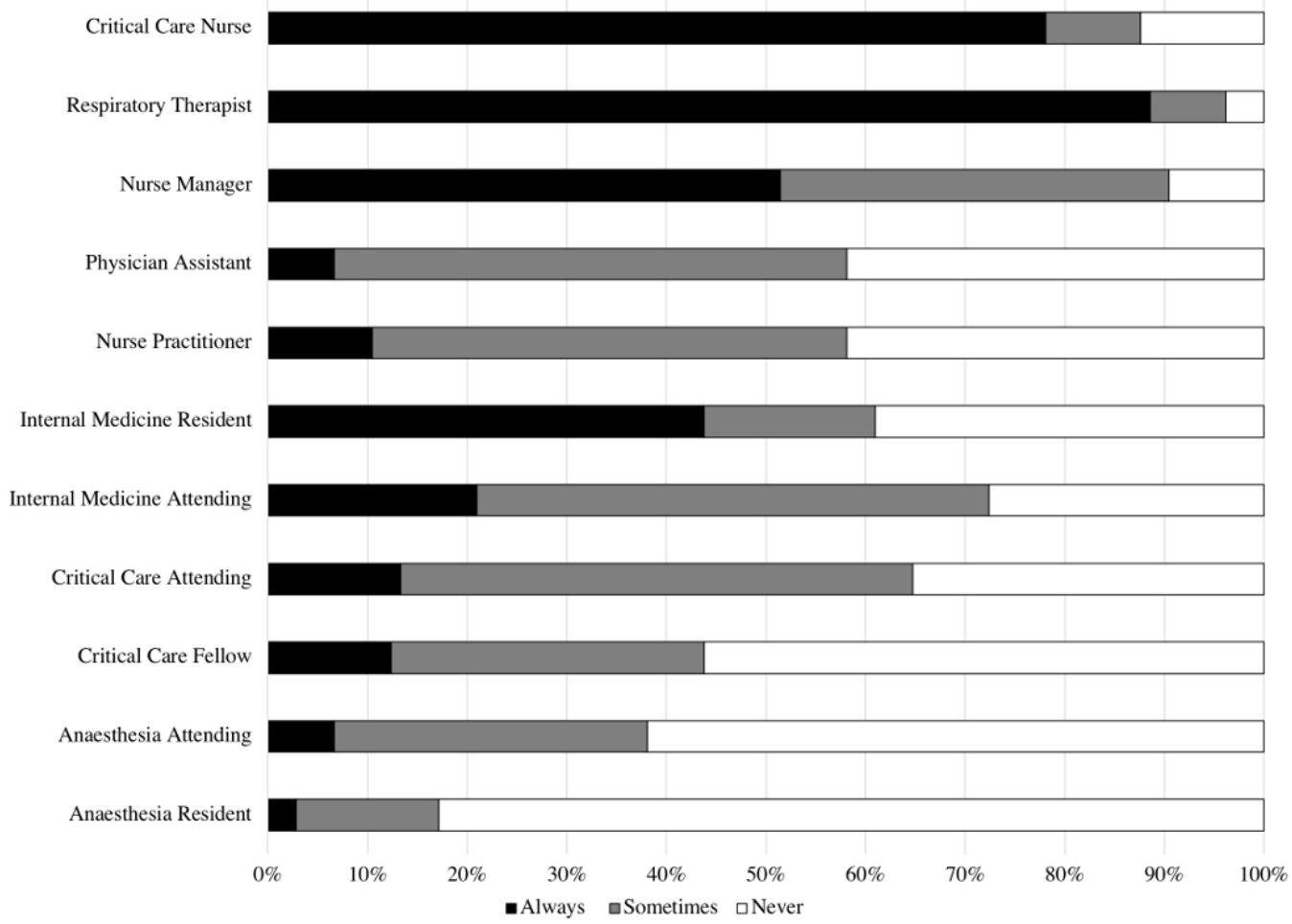

Figure 1 Composition of rapid response teams by specialty. 
Table 3 Individual who was reported to usually lead the RRT and cardiac arrest team by specialty and training level

Team leader by specialty

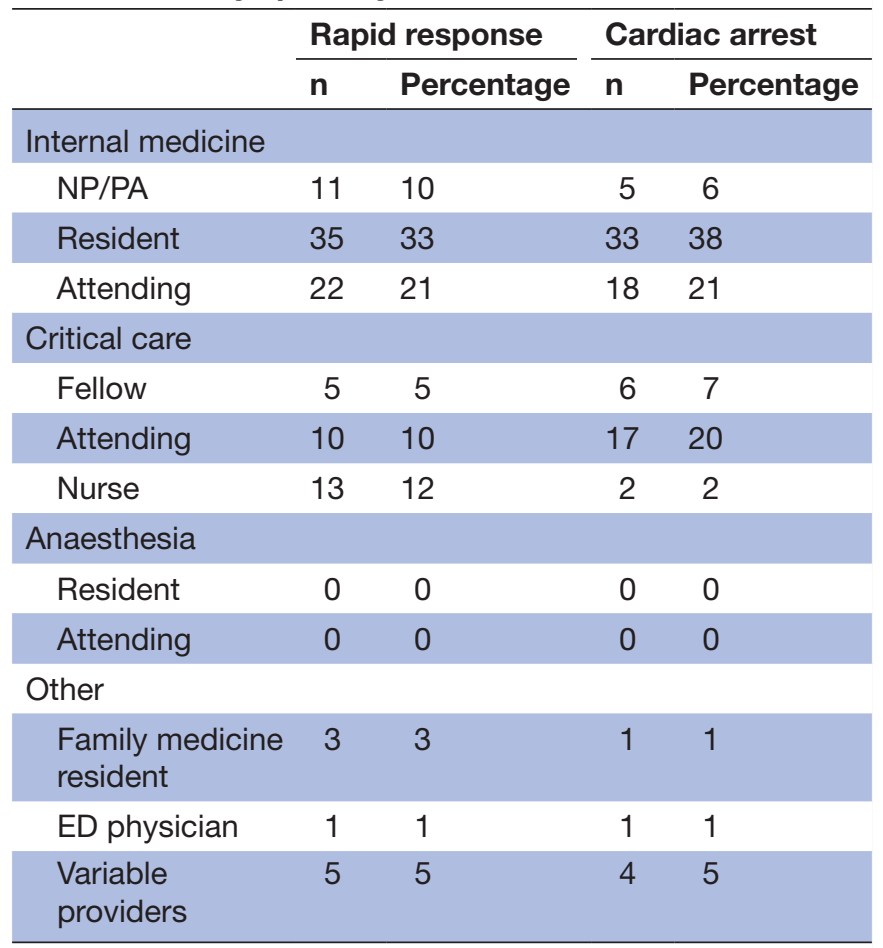

ED, emergency department; NP, nurse practitioner; PA, physician assistant; RRT, rapid response team.
$20 \%$ of hospitals and never attended in $25 \%$. The size of the hospital was not associated with having consistent presence of attending physicians or critical care physicians as part of their RRT ( $p=0.89$ and $p=0.30$, respectively). The presence of an ACGME training programme was not significantly associated with consistent attending presence at RRTs $(\mathrm{p}=0.50)$.

\section{RRT leadership}

RRTs were led by an attending physician in $30 \%$, a trainee physician in $41 \%$, a nurse in $12 \%$, and a nurse practitioner or physician assistant (PA) in $10 \%$. The remaining $6 \%$ were led by any physician present at the RRT $(5 \%)$ or an emergency department physician (1\%), (table 3). In 35 out of the 69 hospitals with an ACGME internal medicine residency $(51 \%)$, RRTs were led by internal medicine residents, in six of these hospitals $(17 \%)$ internal medicine attending physicians also always made up part of the RRT, presumably in a supervisory role.

\section{Cardiac arrest teams}

Eighty-seven hospitals $(81 \%)$ had a dedicated cardiac arrest team. The most common method to call a cardiac arrest team was overhead $(91 \%)$, followed by pager $(68 \%)$ and phone $(9 \%)$. Sixty percent of hospitals used both overhead call and pager. As with RRTs, membership of cardiac arrest teams varied widely (figure 2). Senior physicians were slightly more likely to lead cardiac arrests ( $40 \%$ of cardiac arrest teams compared with $31 \%$ of RRTs) with critical care attendings leading $20 \%$ of cardiac arrest

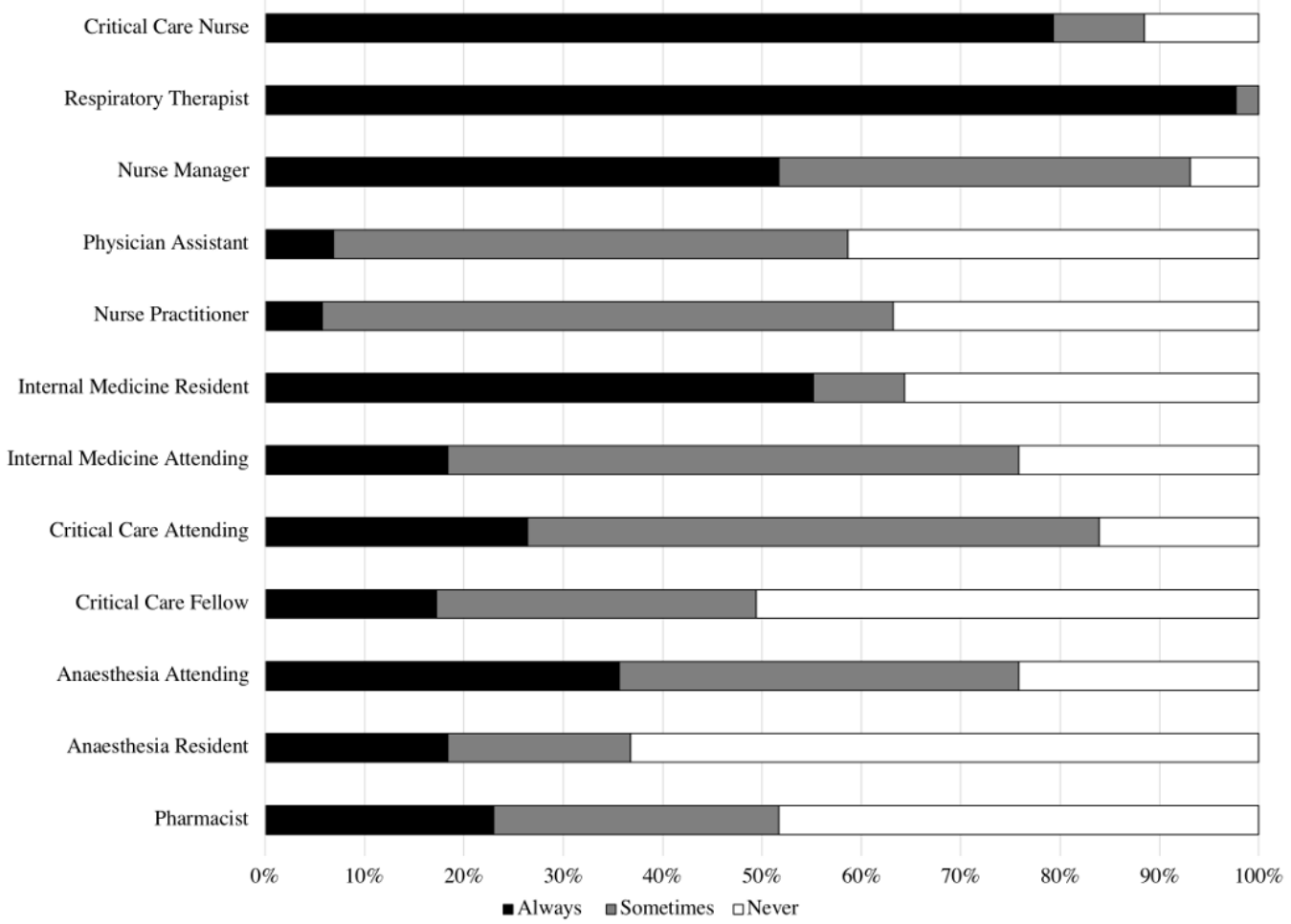

Figure 2 Composition of cardiac arrest teams by specialty. 
teams compared with $10 \%$ of RRTs and nurses leading only $2 \%$ of cardiac arrests (table 3 ).

\section{DISCUSSION}

RRTs aim to provide rapid deployment of skilled healthcare professionals to the bedside of a critically unwell patient in order to simultaneously assess, triage and intervene to prevent further deterioration. For such an intervention to be effective, patients must be identified early in their clinical course, correctly diagnosed and expeditiously treated. While there has been broad adoption of the RRT model, there is no clear guideline-based 'best practices' statement regarding team composition, dynamics or activation criteria, which may contribute to the variability in the effectiveness reported by singlecentre studies of RRTs. Factors that have been associated with top performing cardiac arrest teams include team design, team composition, communication and leadership during cardiac arrest and training of the cardiac arrest team. 15

We here report the results of the largest study in the USA, demonstrating substantial interhospital variations in the activation, constitution and functioning of RRT and cardiac arrest teams.

The choice of activation criteria is paramount to the success of the team. Ideally, such criteria allow for accurate and early identification of patients while avoiding excessive false alarms. We found that the most commonly used activation criteria were clinical concern and single vital sign abnormalities. EWS, which are calculated from routinely collected vital signs, are extensively studied and have been shown to outperform single vital sign abnormalities in predicting adverse clinical outcomes. ${ }^{16}$ Introduction of EWS has been associated with reduction in cardiac arrest rates and inpatient mortality. ${ }^{17-23}$ Despite the evidence supporting the use of EWS to reduce adverse clinical outcomes, we found that they were only used in $59 \%$ of centres in this survey. Broader adoption of EWS as a trigger for activating RRTs might help in standardising the way deteriorating patients are identified early in their trajectory.

Almost all RRTs were available around the clock, however team membership varied considerably and RRT members changed daily in the vast majority. The effect of frequent team turnover in RRTs has not been studied, but one-off teams are known to perform particularly poorly and the beneficial effects of increasing team familiarity are well described in fields outside of medicine and improved cardiac arrest team communication has been associated with top-performing cardiac arrest teams. ${ }^{15} 24$ Given this, maintaining a consistent RRT with familiar members may improve team dynamics. Individual hospital requirements and resources will certainly impact on their ability to support such a team. An RRT huddle at the beginning of each shift, describing individual roles and responsibilities, may help to preserve team dynamics and efficient communication despite this turnover. ${ }^{26}$
One of the appealing features of RRTs is the rapid delivery of skilled healthcare practitioners and critical care expertise to the bedside, in essence a projection of ICU level of care to the medical floors. In practice, we found that lack of consistent attending physician presence was commonplace, even in hospitals where RRTs were led by resident physicians with only 1-3years of postgraduate experience. Although some studies have suggested that the addition of an senior critical care physician to the RRT does not improve mortality, ${ }^{27} 28$ the inclusion of an attending critical care physician ensures attending supervision of the RRT or cardiac arrest, improves documentation, and is associated with high survival rates. ${ }^{29}$ We expected that smaller hospitals would be more stretched for resources and as such less likely have senior physicians at RRTs, but we did not find any association between the size of hospital, number of ICU beds, or presence of an ACGME training programme and the consistent presence of senior physicians. The impact of the lack of senior support at these low frequency, high stakes scenarios may weaken RRT effectiveness and is an area deserving of future research.

Our study has several weaknesses. First and most importantly, it is a survey that was only completed by a single individual at each hospital. While we made every effort to ensure that the survey was only completed by one person per hospital and that the person completing the form would be able to do so correctly, we were unable to verify this due to anonymous nature of the survey.

Our response rate of $35 \%$ is a substantial limitation to the generalisability of our findings. As the survey was anonymous, we were unable to assess the variation in location, resources and affiliation between responders and non-responders. It is unclear whether there was any difference between hospitals who responded and those that did not, although a lower proportion of small hospitals completed surveys, which limits our results further. Smaller hospitals may have fewer resources, more limited physician availability, and a lower number of RRT events when compared with larger hospitals and factors such as these may affect their approach to the RRT composition and availability.

The study included only Medicare-participating hospitals in New York, Pennsylvania, Rhode Island, Vermont, and New Jersey and our findings cannot necessarily be extrapolated to the practice of hospitals across the country or internationally. Variation in RRT and cardiac arrest team composition, as well as activation criteria, has been demonstrated in small studies in a number of other countries, suggesting that such variation is not a unique finding, an area of future study for our group. ${ }^{30-32}$

When assessing the evidence concerning the clinical impact of RRTs, it is important to remember that the RRT is only part of the inpatient chain of rescue. For the best outcome and ideal RRT, multiple factors must be met: the team must be called early, whether by EWS or other track and trigger score; the patient must be diagnosed correctly and managed promptly by experienced clinicians; and the team must work smoothly and communicate well. 


\section{CONCLUSION}

RRTs have become almost ubiquitous across the USA, despite the uncertainty of their impact. As the largest study to date, we have demonstrated considerable heterogeneity among RRTs and cardiac arrest teams, a factor that likely contributes to the mixed results seen in studies. Increased use of EWS, optimising team dynamics and ensuring that trainee team leaders are adequately supported may improve RRT function and patient safety. Individual factors that influence the effectiveness of the RRT, including the importance of leadership, member turnover, and team composition on RRT and cardiac arrest team outcome. The creation of consensus guidelines regarding RRT and cardiac arrest team membership could serve to standardise RRT and cardiac arrest team composition and function across the country.

Contributors OJLM, LEE and VM designed the study. OJLM, CWM, JMH and VM collected and analysed the data. OJLM, CWM, JMH, LEE and VM wrote the manuscript and agree to its submission for publication. All authors were involved in the writing of the manuscript and have drafted, reviewed and approved the current version. All authors agree to be accountable for all aspects of the work in ensuring that questions related to the accuracy or integrity of any part of the work are appropriately investigated and resolved.

Funding The authors have not declared a specific grant for this research from any funding agency in the public, commercial or not-for-profit sectors.

Competing interests None declared.

Patient consent for publication Not required.

Ethics approval This study was reviewed and approved by the New York University School of Medicine's Office of Science and Research Institutional Review Board (i17-01584).

Provenance and peer review Not commissioned; externally peer reviewed.

Data sharing statement Data will not be published publicly. Please contact Oscar Mitchell at oscar.mitchell@nyumc.org if access to the original data is required.

Open access This is an open access article distributed in accordance with the Creative Commons Attribution Non Commercial (CC BY-NC 4.0) license, which permits others to distribute, remix, adapt, build upon this work non-commercially, and license their derivative works on different terms, provided the original work is properly cited, appropriate credit is given, any changes made indicated, and the use is non-commercial. See: http://creativecommons.org/licenses/by-nc/4.0/.

\section{REFERENCES}

1. Institute for Healthcare Improvement. 5 Million Lives campaign. 2006 http://www.ihi.org/about/documents/5millionlivescampaigncasesta tement.pdf (accessed 10 Mar 2018).

2. Chan PS, Khalid A, Longmore LS, et al. Hospital-wide code rates and mortality before and after implementation of a rapid response team. JAMA 2008;300:2506-13.

3. Jones D, Drennan K, Hart GK, et al. Rapid Response Team composition, resourcing and calling criteria in Australia. Resuscitation 2012;83:563-7.

4. Stolldorf DP, Jones CB. Deployment of rapid response teams by 31 hospitals in a statewide collaborative. Jt Comm J Qual Patient Saf 2015;41:186-AP3.

5. Bellomo R, Goldsmith D, Uchino S, et al. A prospective before-andafter trial of a medical emergency team. Med J Aust 2003;179:283-7.

6. DeVita MA, Braithwaite RS, Mahidhara R, et al. Use of medical emergency team responses to reduce hospital cardiopulmonary arrests. Qual Saf Health Care 2004;13:251-4.

7. Buist M, Harrison J, Abaloz E, et al. Six year audit of cardiac arrests and medical emergency team calls in an Australian outer metropolitan teaching hospital. BMJ 2007;335:1210-2.

8. Dacey MJ, Mirza ER, Wilcox V, et al. The effect of a rapid response team on major clinical outcome measures in a community hospital. Crit Care Med 2007;35:2076-82.
9. Offner PJ, Heit J, Roberts R. Implementation of a rapid response team decreases cardiac arrest outside of the intensive care unit. $J$ Trauma 2007;62:1223-8.

10. Sharek PJ, Parast LM, Leong $\mathrm{K}$, et al. Effect of a rapid response team on hospital-wide mortality and code rates outside the ICU in a Children's Hospital. JAMA 2007;298:2267-74.

11. Ludikhuize J, Brunsveld-Reinders AH, Dijkgraaf MG, et al. Outcomes associated with the nationwide introduction of rapid response systems in the netherlands. Crit Care Med 2015;43:2544-51.

12. Hillman K, Chen J, Cretikos M, et al. Introduction of the medical emergency team (MET) system: a cluster-randomised controlled trial. Lancet 2005;365:2091-7.

13. Chan PS, Jain R, Nallmothu BK, et al. Rapid response teams: a systematic review and meta-analysis. Arch Intern Med 2010;170:18-26.

14. Edelson DP, Yuen TC, Mancini ME, et al. Hospital cardiac arrest resuscitation practice in the United States: a nationally representative survey. J Hosp Med 2014;9:353-7.

15. Nallamothu BK, Guetterman TC, Harrod M, et al. How do resuscitation teams at top-performing hospitals for in-hospital cardiac arrest succeed? A qualitative study. Circulation 2018;138:154-63.

16. Jarvis S, Kovacs C, Briggs J, et al. Aggregate National Early Warning Score (NEWS) values are more important than high scores for a single vital signs parameter for discriminating the risk of adverse outcomes. Resuscitation 2015;87:75-80.

17. Gardner-Thorpe J, Love N, Wrightson J, et al. The value of Modified Early Warning Score (MEWS) in surgical in-patients: a prospective observational study. Ann $R$ Coll Surg Engl 2006;88:571-5.

18. Paterson R, MacLeod DC, Thetford D, et al. Prediction of in-hospital mortality and length of stay using an early warning scoring system: clinical audit. Clin Med 2006;6:281-4.

19. Groarke JD, Gallagher J, Stack J, et al. Use of an admission early warning score to predict patient morbidity and mortality and treatment success. Emerg Med J 2008;25:803-6.

20. Cei M, Bartolomei C, Mumoli N. In-hospital mortality and morbidity of elderly medical patients can be predicted at admission by the Modified Early Warning Score: a prospective study. Int J Clin Pract 2009;63:591-5.

21. Maupin JM, Roth DJ, Krapes JM. Use of the modified early warning score decreases code blue events. Jt Comm J Qual Patient Saf 2009;35:598-603.

22. Moon A, Cosgrove JF, Lea D, et al. An eight year audit before and after the introduction of modified early warning score (MEWS) charts, of patients admitted to a tertiary referral intensive care unit after CPR. Resuscitation 2011;82:150-4.

23. Nishijima I, Oyadomari S, Maedomari S, et al. Use of a modified early warning score system to reduce the rate of in-hospital cardiac arrest. J Intensive Care 2016;4:12.

24. HARRISON DA, Mohammed S, McGrath JE, et al. Time matters in team performance: Effects of member familiarity, entrainment, and task discontinuity on speed and quality. Pers Psychol 2003;56:633-69.

25. Huckman RS, Staats BR, Upton DM. Team familiarity, role experience, and performance: evidence from indian software services. Manage Sci 2009;55:85-100.

26. Shapiro J, Venkata A, Ochieng P, et al. The Emergency Department to ICU Quality and Safety Project Formal Handoff/Huddle to Improve Care: 43rd Annual Critical Care Congress, 2013.

27. Karvellas CJ, de Souza IA, Gibney RT, et al. Association between implementation of an intensivist-led medical emergency team and mortality. BMJ Qual Saf 2012;21:152-9.

28. Morris DS, Schweickert W, Holena D, et al. Differences in outcomes between ICU attending and senior resident physician led medical emergency team responses. Resuscitation 2012;83:1434-7.

29. Romig M, Duval-Arnould J, Winters BD, et al. Intensivist Presence at Code Events Is Associated with High Survival and Increased Documentation Rates. Crit Care Clin 2018;34:259-66.

30. Psirides A, Hill J, Hurford S. A review of rapid response team activation parameters in New Zealand hospitals. Resuscitation 2013;84:1040-4.

31. Tirkkonen J, Nurmi J, Olkkola KT, et al. Cardiac arrest teams and medical emergency teams in Finland: a nationwide cross-sectional postal survey. Acta Anaesthesiol Scand 2014;58:420-7.

32. Lauridsen KG, Schmidt AS, Adelborg K, et al. Organisation of inhospital cardiac arrest teams - a nationwide study. Resuscitation 2015;89:123-8. 